Proceedings

\title{
A Sonochemically-Synthesized Microporous Metal- Organic Framework for the Rapid and Efficient Ultrasonic-Assisted Removal of Mercury (II) Ions in a Water Solution and a Study of the Antibacterial Activity ${ }^{+}$
}

\author{
Ehsan Moradi 1,*, Rahmatollah Rahimi 1,*, Vahid Safarifard ${ }^{1, *}$ and Shahram Azari ${ }^{2}$ \\ 1 Department of Chemistry, Iran University of Science and Technology, Tehran 16846-13114, Iran \\ 2 National Cell Bank of Iran, Pasteur Institute of Iran, Tehran 16846-13114, Iran; azarish2000@yahoo.com \\ * Correspondence: moradi_e@alumni.iust.ac.ir (E.M.); rahimi_rah@iust.ac.ir (R.R.); \\ vsafarifard@iust.ac.ir (V.S.); Tel.: +98-217-724-0290 (R.R.); Fax: +98-217-749-1204 (R.R.) \\ + Presented at the 23rd International Electronic Conference on Synthetic Organic Chemistry, \\ 15 November-15 December 2019; Available online: https://ecsoc-23.sciforum.net/.
}

Published: 14 November 2019

\begin{abstract}
Nowadays, water pollution due to heavy metal ions is a great concern in all human communities. In this project, a metal-organic frameworks (MOFs), which were named $\mathrm{Zn} 2(\mathrm{oba}) 2 \mathrm{bpy}$, $\left(\mathbf{1} ; \mathrm{H}_{2} \mathrm{oba}=4\right.$,4-oxybisbenzoic acid and bpy =4,4-bipyridine) linkers, were successfully synthesized. The properties of these MOFs were investigated using different techniques, such as FT-IR, XRD, and SEM analysis. The frameworks have special characteristics, like the rapid, efficient, and selective removal of metal ions from contaminated water. The use of an ultrasonic device plays an important role in shortening the absorption time of mercury (II) ions by increasing absorbent dispersion in the solution. The adsorption capacity was affected by variables such as the $\mathrm{pH}$ of the solution, $\mathrm{Hg}^{2+}$ initial concentration, adsorbent dosage, and contact time. For $\mathrm{Hg}$ (II) metal ions, the sorption capacity of $338 \mathrm{mgg}^{-1}$ was effectively obtained by $\mathrm{Zn}_{2}(\mathrm{oba})_{2} \mathrm{bpy}$ structures. The experimental adsorption data for the $\mathrm{Zn}_{2}(\mathrm{oba})_{2} \mathrm{bpy} \mathrm{MOF}$ is well-suited to the pseudo-second-order kinetic model $\left(\mathrm{R}^{2}=0.99\right)$, and the adsorption isotherms of $\mathrm{Hg}^{2+}$ metal ions are in good agreement with the Langmuir model. This work displays the effective removal of $\mathrm{Hg}^{2+}$ ions from pollutant water in under $30 \mathrm{~min}$. The antibacterial activities of $\mathrm{Zn}_{2}(\mathrm{oba})_{2} \mathrm{bpy}(\mathbf{1})$ were tested against gram-positive and gram-negative species. The as-synthesized 1 exhibited excellent antibacterial effectiveness against Escherichia coli and Staphylococcus aureus.
\end{abstract}

Keywords: metal-organic framework; ultrasound; removal; $\mathrm{Hg}^{2+}$

\section{Highlights}

- Sonochemically microporous metal-organic framework $\left(\mathrm{Zn}_{2}(\mathrm{oba})_{2}(\mathrm{bpy})\right)(\mathbf{1})$ was synthesized;

- $\mathrm{Zn}_{2}$ (oba)2 (bpy) (1) MOF showed the maximum absorption of $\mathrm{Hg}^{2+}$ ions at $\mathrm{pH}=5$;

- The absorption kinetics was followed by the pseudo-second-order model;

- The adsorption isotherm was followed by the Langmuir model;

- The maximum absorption capacity for this framework was $338 \mathrm{mgg}^{-1}$ for $\mathrm{Zn}_{2}(\mathrm{oba})_{2}$ (bpy) (1), which was achieved in less than $30 \mathrm{~min}$;

- $\quad$ The antibacterial activity study of $\mathrm{Zn}_{2}(\mathrm{oba})_{2}(\mathrm{bpy})(\mathbf{1})$. 


\section{Introduction}

Among various heavy metal ions, mercury (II) is known to cause acute and chronic poisoning, and also has the ability to target almost all organs of the body, especially the central nervous system [1-3]. Because of these reasons, the adsorption of mercury (II) from contaminated water systems is very important [4]. Over the past two decades, different types of methods, including membrane filtration, ion exchange, chemical precipitation, electrochemical treatment technologies, and adsorption, have been used to remove metal ions [5]. Recently, the absorption method has been shown to be an effective solution for the removal of heavy metals. The absorption method is a simple, low-cost, and high-performance method that can be used on a large scale [6]. These properties of the absorption method depend on various factors, such as the solution $\mathrm{pH}$, adsorbent dosage, contact time, ionic strength, background electrolyte, temperature, and nature of the adsorbent [7,8]. Different adsorbents have been used to absorb metal ions from water [9-11]. Conventional adsorbents have deficiencies, such as high operating and maintenance costs, the emission of secondary pollutants and, most importantly, a poor performance at very low concentrations. The preparation of metal-organic frameworks (MOFs) is an effective method for the absorption and selective separation of metal ions from water [12-15]. An MOF is a solid absorbent material made of secondary building units (SBUs), which includes metal clusters and organic linkers that create three-dimensional grids $[16,17]$. The selection of metals and linkers has a great influence on the structure and properties of MOFs [18]. These MOFs are characterized by large-sized cavities, high surface areas, the selectable absorption of small molecules, controllable particle dimensions and morphology, etc., which have attracted the attention of researchers [19]. These features have promising results in applications such as sensing [20-22], gas storage [23], separation [24], drug delivery [25], and catalysis [26]. The use of MOFs is a growing approach for removing pollutants from water. The ultrasonic technique has been used to increase and improve mass transfer [27]. The ultrasound power can accelerate the absorption process [28,29]. Cavitation (nucleus, growth, and collapse of small gas bubbles) and the high-pressure variation caused by ultrasound can cause this phenomenon [30]. In addition, by developing effective in-particle interaction using physical phenomena such as micro-turbulences, microstreaming, acoustic waves, and microjets, the chemical reactivity of particles in the solution can be improved [31]. Ultrasound has been proven to be a very useful tool for accelerating the absorption of metal ions and paint on adsorbents by enhancing the dependence between an adsorbate and adsorbent [32-36]. In this study, a $\mathrm{Zn}_{2}\left(\mathrm{oba}\right.$ ) 2bpy (1) MOF with $\mathrm{H}_{2} \mathrm{Oba}=4,4$-oxybisbenzoic acid and bpy = 4,4-bipyridine linkers was synthesized to remove mercury (II) ions from water. We evaluated the contact time, $\mathrm{pH}$ parameters, adsorbent dosage, and concentrations of mercury (II) metal ions. In this paper, we show that nanoporous materials can play an effective role in the selective and effective removal of heavy metal ions from water.

\section{Experimental Section}

\subsection{Materials and Measurements}

All materials used during synthesis were purchased from a commercial provider. The infrared spectra were collected with a Nicolet 100 Fourier transform infrared (FTIR) spectrometer in the range of $400-4000 \mathrm{~cm}^{-1}$. Powder X-ray diffraction (PXRD) measurements were done by using a Philips $X^{\prime}$ Pert diffractometer with monochromated $\mathrm{Cu} \mathrm{K} \alpha$ radiation $(\lambda=1.54056 \AA)$. Inductively coupled plasma atomic emission spectrometry (ICP-AES) on a Varian Vista-PRO instrument, equipped with a charge-coupled detector, was used to determine the remaining concentration of metal ions.

\subsection{Solvothermal Synthesis of $\mathrm{Zn}_{2}(o b a)_{2}(b p y)(\mathbf{1})$}

$\mathrm{Zn}\left(\mathrm{NO}_{3}\right)_{2} .6 \mathrm{H}_{2} \mathrm{O}(0.116 \mathrm{~g}, 0.5 \mathrm{mmol}), 4,4$-oxybisbenzoicacid $(0.129 \mathrm{~g}, 0.5 \mathrm{mmol})$, and 4,4bipyridine $(0.074 \mathrm{~g}, 0.25 \mathrm{mmol})$ were dissolved in $10 \mathrm{~mL} \mathrm{~N}, \mathrm{~N}$-dimethylformamide (DMF) in a $20 \mathrm{~mL}$ glass vial. The mixture was stirred under sonication for $10 \mathrm{~min}$ to obtain a clear solution. The sealed 
vial was then placed in an oven and heated at $100{ }^{\circ} \mathrm{C}$ for $48 \mathrm{~h}$. Next, the solid product was filtered and washed with DMF.

\subsection{Sonochemical Synthesis of $Z_{2}(o b a)_{2} b p y(\mathbf{1})$}

To prepare nano-sized $\mathrm{Zn}_{2}$ (oba) 2 (bpy) (1), $25 \mathrm{~mL}$ solution of zinc (II) acetate dihydrate $(0.5 \mathrm{mmol}$, $0.116 \mathrm{~g} ; 0.02 \mathrm{M})$ in DMF was positioned in a high-density ultrasonic probe at ambient temperature and atmospheric pressure. Then, $0.5 \mathrm{mmol}(0.129 \mathrm{~g})$ and $0.25 \mathrm{mmol}(0.074 \mathrm{~g})$ of the ligands $\mathrm{H}_{2} \mathrm{Oba}$ and bpy, respectively, were added to this solution, which was sonicated for $1 \mathrm{~h}$. Moreover, the MOF was prepared in different concentrations of initial reagents of $0.01,0.02$, and $0.04 \mathrm{M}$ using a constant US generator power of $50 \mathrm{~W}$ for a $1 \mathrm{~h}$ irradiation time. The resulting powders were isolated by centrifugation, washed with DMF three times, and dried in air for characterization.

\subsection{Ultrasonic-Assisted Adsorption Experiments}

In the batch absorption test, the effect of different parameters on the absorption performance of (1) was studied. In this way, $50 \mathrm{~mL}$ of mercury solution was added to $10 \mathrm{mg}$ of adsorbent, at room temperature and in ultrasonic baths. $\mathrm{Hg}\left(\mathrm{NO}_{3}\right)_{2}$ was applied as the source of $\mathrm{Hg}$ (II). The solution $\mathrm{pH}$ was adjusted by adding $0.1 \mathrm{~mL}$ of $0.1 \mathrm{M} \mathrm{NaOH}$ or $0.1 \mathrm{M} \mathrm{HCI}$. The mixture was centrifuged for $5 \mathrm{~min}$ after removing the ultrasonic bath. In the next step, sampling from the solution was performed. The total amount of adsorbed heavy-metal ions on $\mathrm{Zn}_{2}(\mathrm{oba})_{2}(\mathrm{bpy})(\mathbf{1})$ and the removal efficiency were calculated from Equations (1) and (2), respectively:

$$
\begin{aligned}
Q_{t} & =\frac{\left(C_{0}-C_{t}\right) V}{m} \\
\% R & =\frac{\left(C_{0}-C_{e}\right)}{C_{0}} \times 100 .
\end{aligned}
$$

In these equations, $C_{0}$ and $C_{e}$ point to the initial and equilibrium concentrations of $\mathrm{Hg}$ (II) ions $\left(\mathrm{mg} \mathrm{L}^{-1}\right)$, respectively; $\mathrm{V}$ refers to the volume (L) of samples; and $\mathrm{m}$ refers to the adsorbent mass $(\mathrm{g})$. The kinetics of the adsorption process on $\mathrm{Zn}_{2}(\mathrm{oba})_{2}(\mathrm{bpy})$ were evaluated by sampling a solution containing mercury and adsorbent ions at intervals of 5-30 min. Additionally, absorbent isotherms of $\mathrm{Zn}_{2}(\mathrm{oba})_{2}(\mathrm{bpy})$ were evaluated by adding $10 \mathrm{mg}$ of adsorbent to various concentrations ( 5 to 120

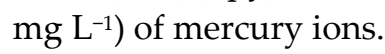

\section{Results and Discussion}

\subsection{Characterization of $\mathrm{Zn}_{2}(\mathrm{oba})_{2}(\mathrm{bpy})(\mathbf{1})$}

The compound $\mathrm{Zn}_{2}(\mathrm{oba})_{2}(\mathrm{bpy})$ (1) was sonochemically synthesized by mixing zinc acetate, 4,4oxybis(benzoic acid) ( $\mathrm{H}_{2} \mathrm{oba}$ ), 4,4-bipyridine (bpy), and DMF for $1 \mathrm{~h}$. Compound 1 possesses a porous 3D network built from a $\mathrm{Zn}_{2}(\mathrm{oba})_{4}$ paddle-wheel secondary building unit. Each SBU is linked by oba to form a distorted $4^{4} 2 \mathrm{D}$ network. Two identical $4^{4}$ nets interpenetrate to form a layered structure. The bpy acts as a linker between the paddle-wheel units from two adjacent layers to yield a highly sTable 3D framework (Figure 1a). The structure contains 1D open channels running along both the a and $b$ axes. For 1 , the strong vibrations at 1600 and $1590 \mathrm{~cm}^{-1}$ correspond to the asymmetric stretching vibration of the carboxylate group coordinated to the cation, whereas it's symmetric stretching vibrations appear at 1415 and $1371 \mathrm{~cm}^{-1}$ (Figure 1b). The difference in frequency between asymmetric and symmetric stretching vibration is more than $200 \mathrm{~cm}^{-1}$, indicating the bidentate-bridging coordination mode of the carboxylate group [37]. The powder XRD pattern of the resulting ultrasound synthesized product (Figure 1c) agrees well with the literature value [38]. Moreover, the sonochemically as-prepared 1 was also monitored by TG analysis (Figure 1d). The weight loss of the guest molecule (DMF) started at $250{ }^{\circ} \mathrm{C}$ and the framework was stable up to $400{ }^{\circ} \mathrm{C}$, before it collapsed, implying the good thermal stability of this MOF [39]. The morphology and sizes of nanostructures prepared using ultrasonic techniques (US techniques) are dependent on various parameters, such as the concentration of initial reagents [40]. In order to investigate the role of this 
parameter in the morphology and size of the MOF, $\mathbf{1}$ samples prepared by the US method using a different concentration of initial reagents were characterized by scanning electron microscopy (SEM). Figure 2 shows the SEM of the MOF prepared in different concentrations of initial reagents of 0.01 , 0.02 , and $0.04 \mathrm{M}$ using a constant US generator power of $50 \mathrm{~W}$ for a $\mathbf{1} \mathrm{h}$ irradiation time. The comparison of the samples with different concentrations shows that high concentrations of initial reagents decreased the particle size (Figure 2c,d). Interestingly, the size of 1 particle formed without US irradiation is much larger than that with US irradiation (Figure 2e,f). In addition, no formation of nanostructures was confirmed. From these results, it is suggested that US cavitation affects the formation of small and uniform 1 nanostructures [41]. Such a size difference is commonly observed in sonochemistry [42]. One explanation for this is that the fast kinetics does not permit the growth of the nuclei, and in each collapsing bubble, a few nucleation centers are formed, whose growth is limited by the short collapse [18].

(a)

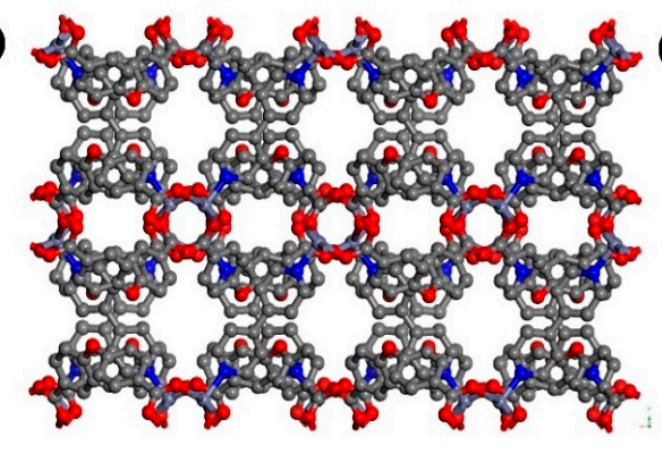

(b)
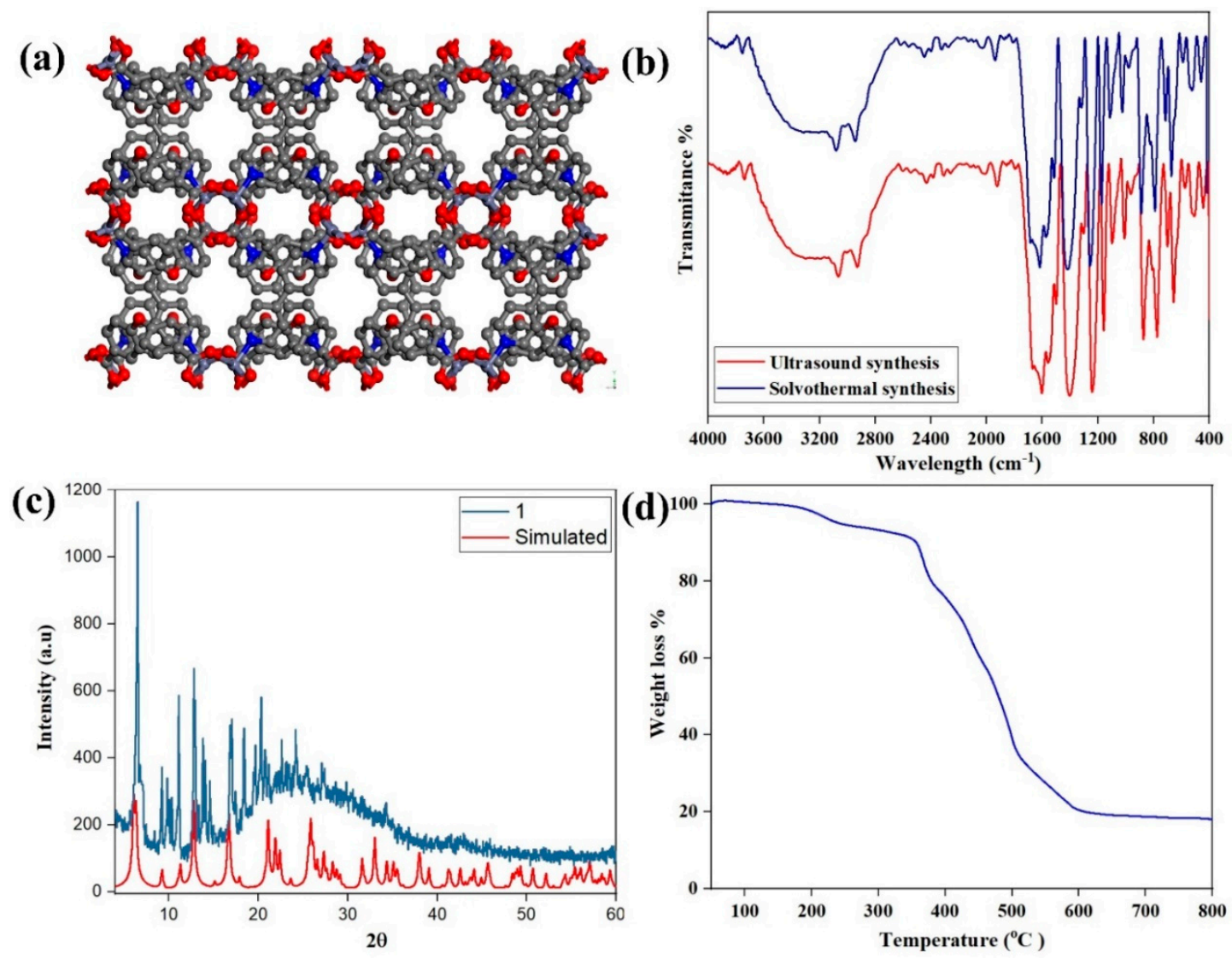

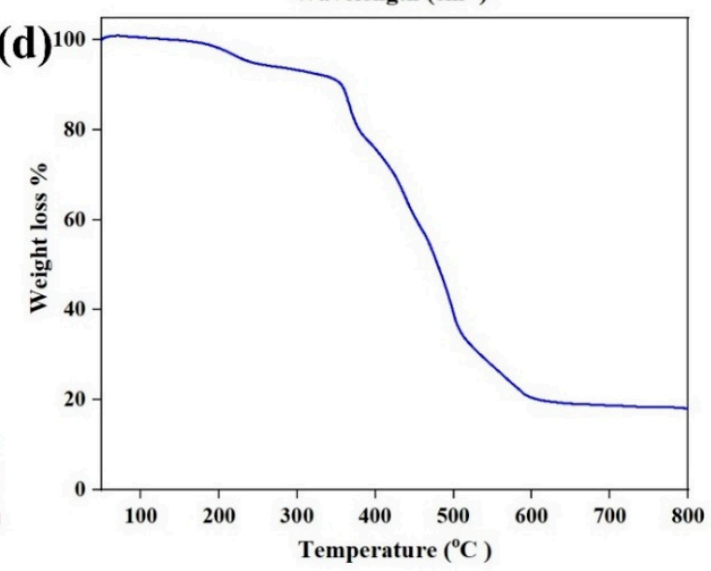

Figure 1. (a) Crystal structure of the 3D framework $Z n_{2}(o b a)_{2}(b p y)$ (1), showing the $1 \mathrm{D}$ channels running along the $a$ axis (the disordered guest molecules are omitted for clarity). (b) FT-IR spectra of sonochemical (red) and solvothermal (blue) synthesized 1. (c) Powder X-ray diffraction (PXRD) of assynthesized (blue) and simulated (red) Zn2(oba)2(bpy) (1). (d) TGA of activated Zn2(oba)2(bpy) (1).

\section{2. $\mathrm{Hg}(\mathrm{II})$ Adsorption Studies}

The ultrasonic-assisted adsorption of $\mathrm{Hg}$ (II) ions from aqueous solutions using $1 \mathrm{MOF}$ was studied to find the optimal initial concentration of ions, adsorbent dosage, $\mathrm{pH}$, and contact time. All experiments were carried out at room temperature at various conditions, according to the designed experiments. Moreover, our MOF displayed a significantly high adsorption capacity for $\mathrm{Hg}^{2+}$ ions. 

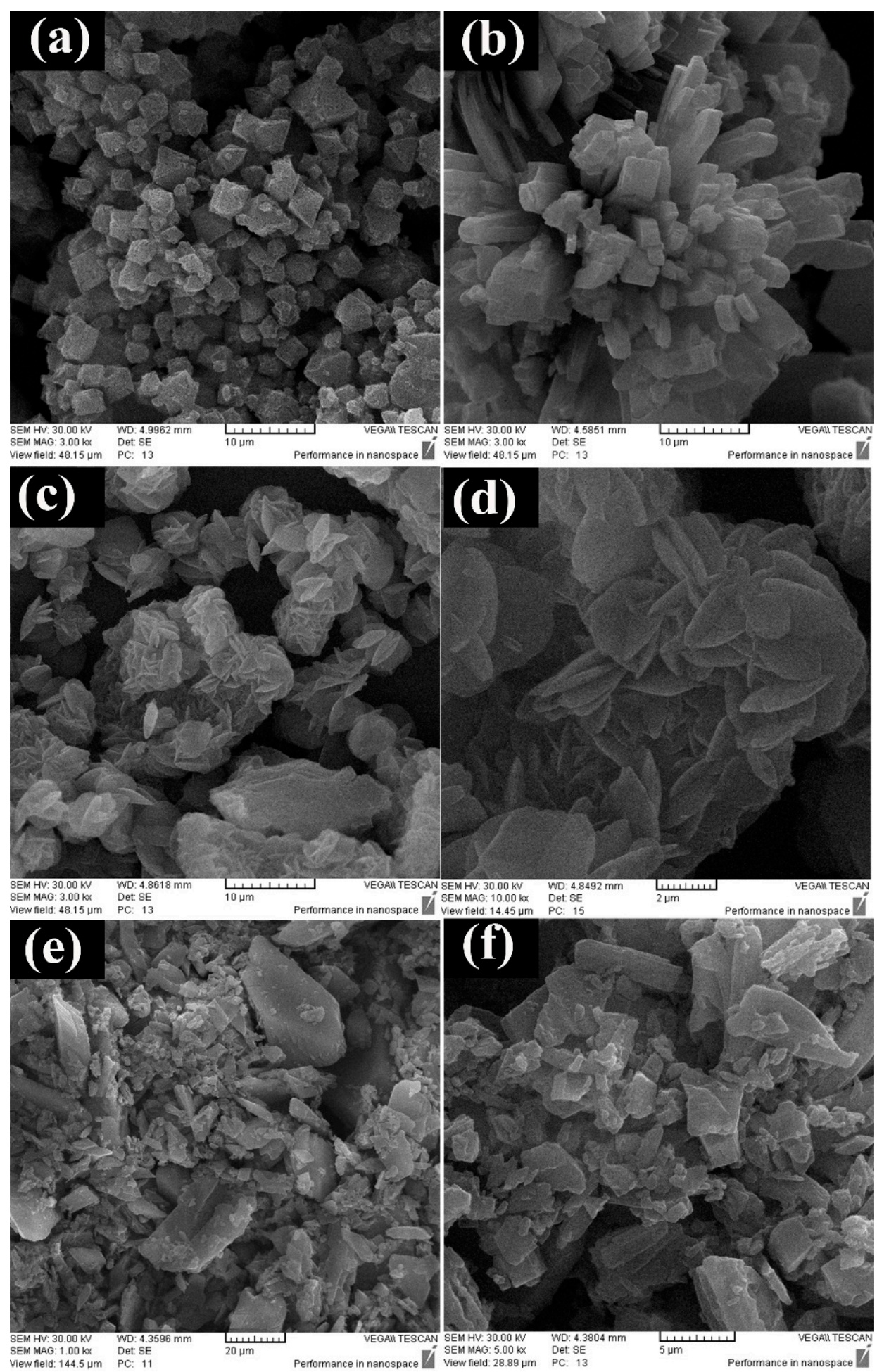

Figure 2. SEM images of $\mathrm{Zn}_{2}(\mathrm{oba})_{2}$ (bpy) (1) nanostructures prepared by a US generator power of 50 $\mathrm{W}$ at a $1 \mathrm{~h}$ irradiation time in different concentrations of initial reagents: (a) $0.01 \mathrm{M},(\mathbf{b}) 0.02 \mathrm{M}$, and (c,d) 0.04 M. (e,f) SEM image of $\mathbf{1}$ bulk powder formed via a solvothermal reaction without ultrasonic irradiation.

\subsection{Effect of $\mathrm{pH}$}

The absorption process strongly depends on the $\mathrm{pH}$. First, $50 \mathrm{ppm}$ of mercury (II) was prepared to investigate the absorption property with 1 . A total of $0.01 \mathrm{~g}$ of absorbent was added to $50 \mathrm{~mL}$ of mercury (II)-containing solution in separate containers. At a low $\mathrm{pH}$, competition between mercury (II) and hydrogen ions for placement on adsorbent sites decreases the absorption rate. By increasing the $\mathrm{pH}$ of the solution, the effect of the competition of $\mathrm{Hg}^{2+}$ and $\mathrm{H}^{+}$is reduced and, as a result, more 
mercury (II) is absorbed. At a higher $\mathrm{pH}$, the amount of $\mathrm{H}^{+}$ions decreased and at $\mathrm{pH}=5$, the maximum amount of mercury (II) adsorption was reached (Figure 3a).

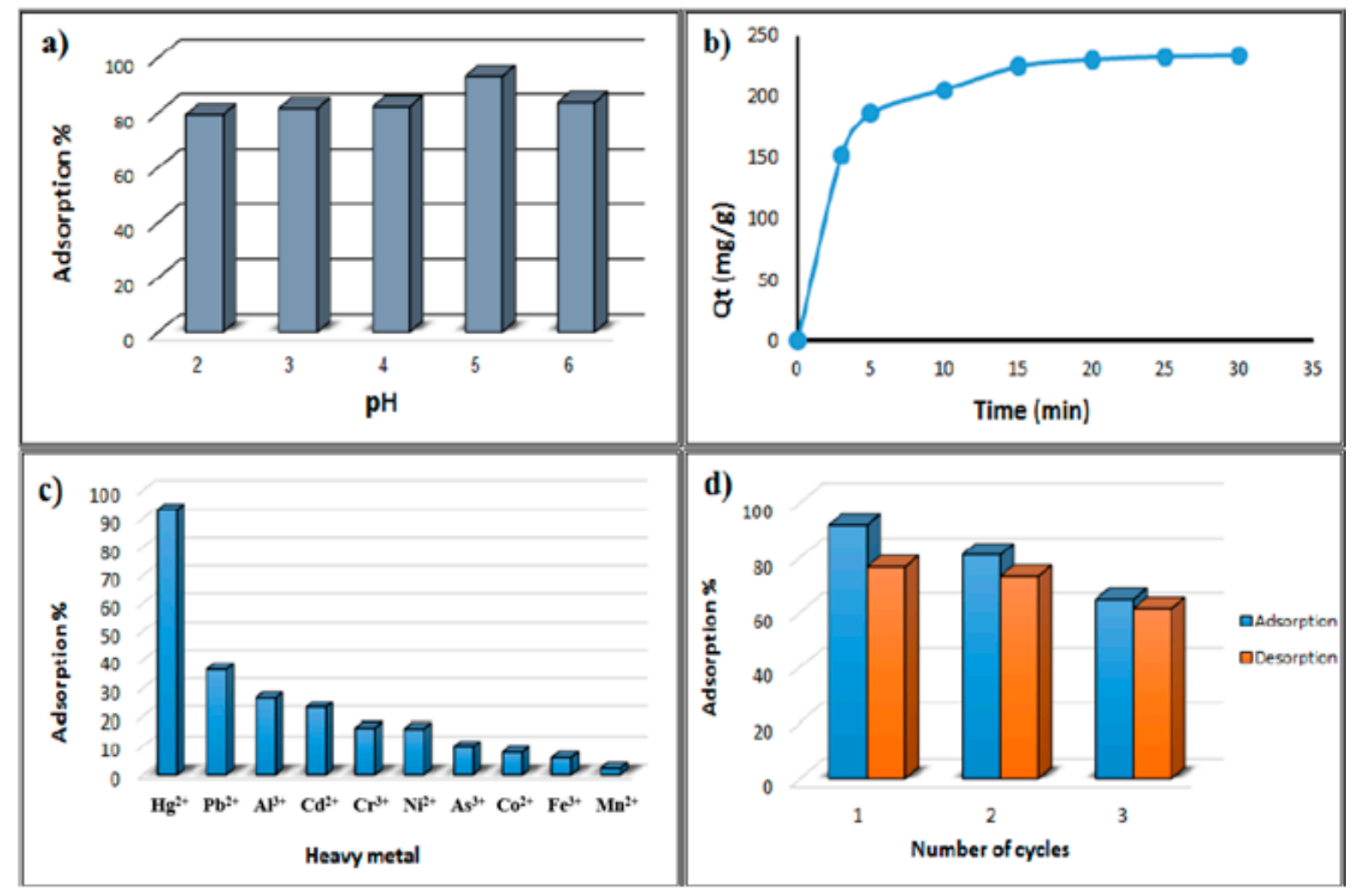

Figure 3. (a) $\mathrm{pH}$ solution effect on the $\mathrm{Hg}(\mathrm{II})$ adsorption efficiency, (b) effect of various contact times on $\mathrm{Hg}$ (II) sorption, (c) comparative adsorption of different heavy-metal ions, and (d) adsorptiondesorption cycles of $\mathrm{Zn}_{2}(\mathrm{oba})_{2}(\mathrm{bpy})$ (1). (The percentage of desorption was calculated based on the amount of adsorption).

\subsection{Study of Sorption Kinetics}

To study the sorption mechanism, which governs the sorption procedure, and to estimate whether the sorption mechanism can be considered a physical or chemical mechanism, various adsorption models, such as intraparticle diffusion, pseudo-first-order, and pseudo-second-order models, were applied to investigate the adsorption data. A high correlation coefficient of the pseudosecond-order model was achieved for $\mathrm{Hg}(\mathrm{II})$ ions $\left(\mathrm{R}^{2}=0.99\right.$ for $\left.\mathbf{1}\right)$, which indicated that this adsorption model is more fitted with the sorption data than the pseudo-first-order model (Figure 4). These results demonstrate that the pseudo-second-order model displays a more satisfactory correlation in comparison with the pseudo-first-order model for the sorption of $\mathrm{Hg}^{2+}$ metal ions, suggesting that the sorption process was predominantly controlled by chemical reactions between the metal ions and the adsorption sites of the MOF [43-45]. The kinetic parameters of $\mathbf{1}$ were evaluated by exploring the impact of various contact times on $\mathrm{Hg}$ (II) sorption. As shown in Figure 3b, fast kinetics was obtained in less than $30 \mathrm{~min}$. The Weber-Morris intraparticle diffusion model was then used to better identify the diffusion mechanism. This model can be ascribed to the mass transfer steps in the $\mathrm{Hg}^{2+}$ ion adsorption onto adsorbents. The plots of $Q_{t}$ versus $t^{1 / 2}$ in the range of the calculated adsorption give a nonlinear curve, which did not pass through the origin $(C \neq 0)$, and shows that the intraparticle diffusion mechanism is not the only rate-determining step (Figure $3 \mathrm{~b}$ ). The initial portion can be assigned to boundary layer diffusion, and the second portion with a lower slope indicated the slow adsorption step, where intraparticle diffusion is involved in the sorption process, but is not the only rate-determining step. The initial portion with a larger slope has a faster rate than the second portion. Additionally, the second part represents the equilibrium level. 


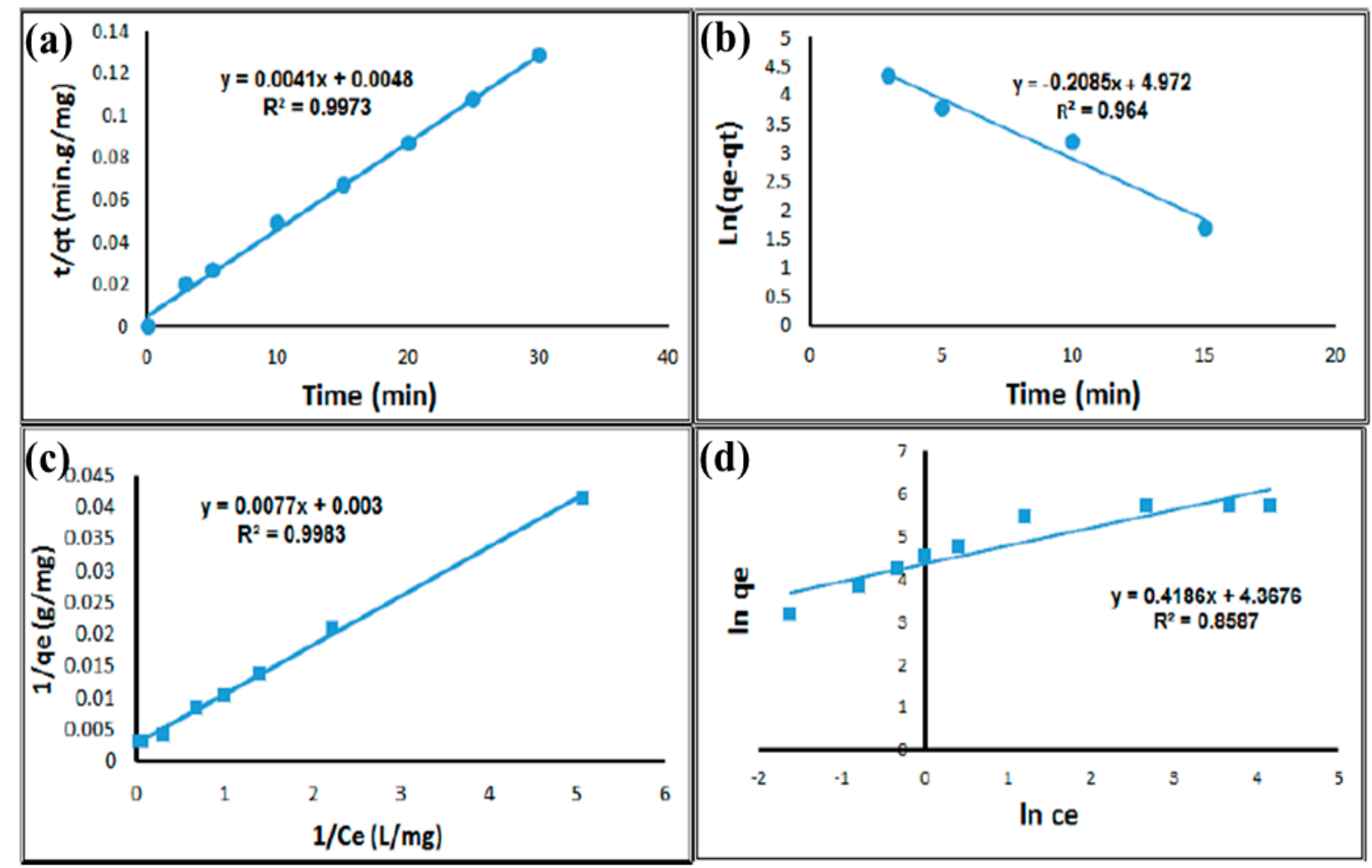

Figure 4. (a) Pseudo-second-order and (b) pseudo-first-order kinetics model $\mathrm{of} \mathrm{Hg}^{2+}$ adsorption on $\mathrm{Zn}_{2}$ (oba) ${ }_{2}$ (bpy) (1), (c) linear curve fitting with the Langmuir model, and (d) linear curve fitting with the Freundlich model for $\mathrm{Hg}^{2+}$ for $\mathrm{Zn}_{2}(\mathrm{oba})_{2}$ (bpy) (1).

\subsection{Adsorption Isotherm}

To achieve significant data for the judicious design of a favorable sorption system, the adsorption tests were performed in seven different initial concentrations (between 5 and $120 \mathrm{ppm}$ ) with $10 \mathrm{mg}$ of adsorbent and then stirred for $30 \mathrm{~min}$ at ambient temperature. To evaluate the efficacy of the sorption process, sorption models, namely, Freundlich and Langmuir models, were employed (Figure 4c,d). Monolayer adsorption is defined by the Langmuir model upon the homogeneous surface of the adsorbent and represented as:

$$
\frac{1}{q_{e}}=\frac{1}{q_{m}}+\frac{1}{\mathrm{~b} q_{m}} \times \frac{1}{\mathrm{Ce}}
$$

where multilayer adsorption is described by the Freundlich model upon the heterogeneous surface of sorbent material and illustrated as:

$$
\mathrm{q}_{\mathrm{e}}=\mathrm{K}_{\mathrm{F}} \mathrm{C}^{1 / \mathrm{n}} \text {, }
$$

where $\mathrm{Ce}\left(\mathrm{mg} \mathrm{L}^{-1}\right)$ is the ion concentration at equilibrium, $\mathrm{b}\left(\mathrm{L} \mathrm{mg}^{-1}\right)$ is devoted to the energy of the sorption process, $\mathrm{q}_{\mathrm{m}}\left(\mathrm{mgg}^{-1}\right)$ points to the maximum sorption capacity obtained for monolayer sorption, and $\mathrm{K}_{\mathrm{F}}$ is the Freundlich constant. The Langmuir model is a better model for explaining the adsorption isotherm based on $\mathrm{R}^{2}$ values. As shown in Figure $4 \mathrm{c}, \mathrm{d}$ the maximum sorption capacity of 1 for $\mathrm{Hg}$ (II) ions was $338 \mathrm{mgg}^{-1}$. The $\mathbf{1}$ reveals an outstanding adsorption performance due to its large adsorption capacity.

\subsection{Effect of Adsorbent Dosage}

Adsorbent dosage had an inverse effect on the adsorption capacity. This is because, at a higher adsorbent dosage, the ratio of the adsorbing concentration to adsorbent sites is lower, which causes a decreasing adsorption capacity. 


\subsection{Investigation of Comparative Adsorption}

Ligands display very fast adsorption and a highly efficient capacity for $\mathrm{Hg}$ (II) removal. In addition, the comparative sorption tests were performed for various metal ions. $\mathrm{Cd}^{2+}, \mathrm{CO}^{2+}, \mathrm{Hg}^{2+}, \mathrm{Cr}^{+3}$, $\mathrm{As}^{3+}, \mathrm{Ni}^{2+}, \mathrm{Fe}^{3+}, \mathrm{Cu}^{2+}$, and $\mathrm{Al}^{3+}$ metal ions were used to study the adsorption performance of this MOF. As illustrated in Figure $3 \mathrm{c}$, the compound $\mathrm{Hg}$ (II) was adsorbed more efficiently in comparison to other metal ions.

\subsection{Reusability Study}

To investigate the reusability of this MOF, three adsorption-desorption cycles were accomplished. Satisfactory results were obtained, as illustrated in Figure 3d. The desorption process was performed by adding $2 \mathrm{~mL}$ of deionized water to the adsorbent, and the solution was stirred for $20 \mathrm{~min}$ at ambient temperature. The amounts of total $\mathrm{Hg}(\mathrm{II})$ metal ions were then determined by ICPAES. The percentage of adsorption obtained after three cycles shows that MOF $\mathbf{1}$ is reusable for absorbing metal ions.

\subsection{Antibacterial Activity}

The antibacterial activity is measured from the inhibition zone. In the present work, Escherichia coli (a gram-negative bacteria) and Staphylococcus aureus (a gram-positive bacteria) were used as the biological agents. This is shown in Figure 5a,b. The results demonstrated a relationship between the $\mathrm{Zn}_{2}(\mathrm{oba})_{2}(\mathrm{bpy})$ (1) concentration and antibacterial activity. The Kirby-Bauer disk diffusion susceptibility test was used to measure the antibacterial activity of $\mathbf{1}$. Colonies of each strain of $E$. coli and S. aureus were cultured overnight on trypticase soy agar medium and transferred through a loop in a sterilized test tube containing $5 \mathrm{~mL}$ of sterilized normal saline solution. The mixture was completely mixed. Then, uniform suspensions of bacteria with 0.5 McFarland turbidity standards were cultured by a swab on Muller Hinton agar. To prepare the disks, $50 \mathrm{mg} \mathrm{mL}^{-1}$ synthesized material was added to sterilized blank disks and left for 2 days. The disks were then seeded onto the plate at appropriate time intervals and incubation was carried out, at $37^{\circ} \mathrm{C}$ for $18 \mathrm{~h}$. Next, the zones of bacterial inhibition were measured. $\mathrm{Zn}^{2+}$ was readily released from the $\mathbf{1}$ structure in water and interacted with the bacterial membrane. 1, therefore, acted as a $\mathrm{Zn}$ ion reservoir. Moreover, the structure underwent gradual degradation, providing sustained ion release. However, the antibacterial test for both bacteria showed an excellent effect against $E$. coli and S. aureus [46-48].

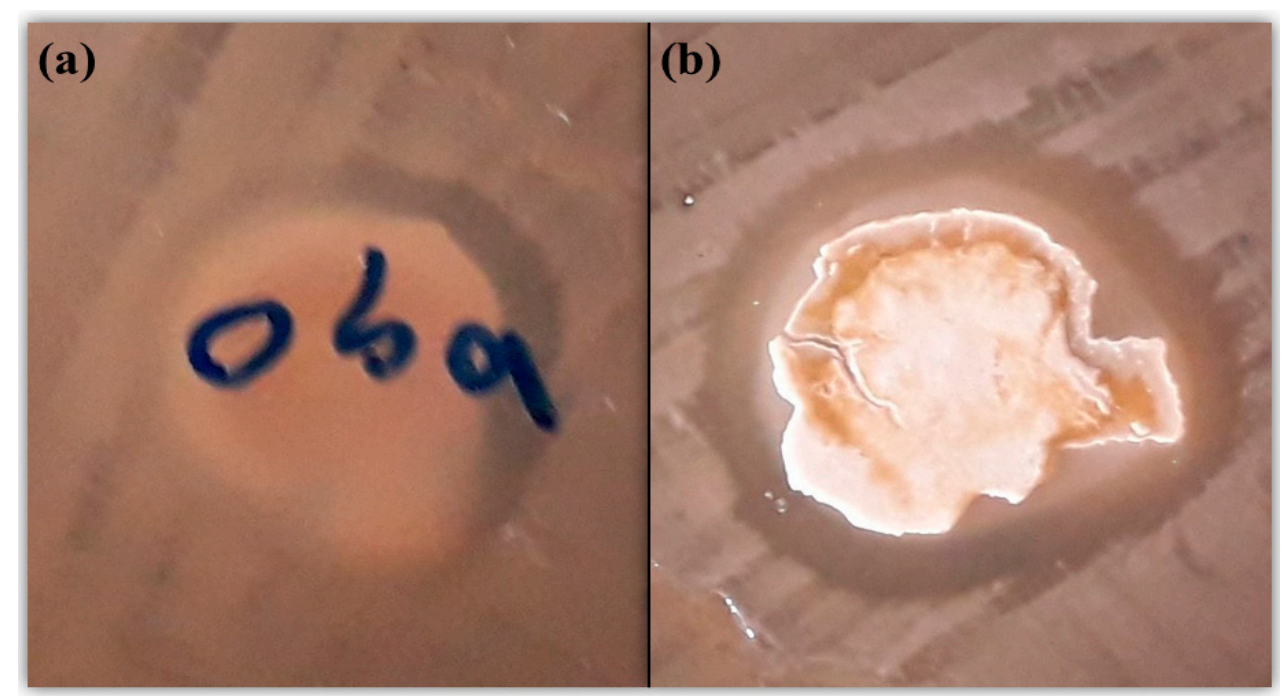

Figure 5. The antibacterial activity zone of inhibition with $\mathrm{Zn}_{2}(\mathrm{oba})_{2}(\mathrm{bpy})$ (1) powders, for different bacterial strains: (a) Escherichia coli and (b) Staphylococcus aureus. 


\section{Conclusions}

In summary, a $\mathrm{Zn}_{2}(\mathrm{oba})_{2} \mathrm{bpy}$ (1) metal-organic framework was synthesized using an organic linker of $\mathrm{H}_{2} \mathrm{Oba}=4,4$-oxybisbenzoic acid and bpy = 4,4-bipyridine, with the target of absorbing mercury(II) ions from water. The results of the absorption experiments showed that the framework has a similar function in absorbing and separating mercury (II) ions. Additionally, the maximum absorption capacity for this framework was $338 \mathrm{mgg}^{-1}$ for $\mathbf{1}$, which was achieved in less than $30 \mathrm{~min}$. Moreover, in comparison with the previous report, $\mathbf{1}$ displayed a higher adsorption capacity for the $\mathrm{Hg}^{2+}$ removal performance. Due to the inability of most adsorbents to absorb metal ions at low initial concentrations, framework 1 provided an acceptable performance. These results indicate that the $\mathrm{H}_{2} \mathrm{oba}=4$,4-oxybisbenzoic acid and bpy $=4$,4-bipyridine ligand-based framework can be considered an adsorbent for the treatment of sewage to recover environmental health. This work effectively removed $\mathrm{Hg}^{2+}$ ions from pollutant water in under $30 \mathrm{~min}$. The antibacterial activities of $\mathrm{Zn}_{2}(\mathrm{oba})_{2} \mathrm{bpy}$ (1) were tested against gram-positive and gram-negative species. The as-prepared $\mathbf{1}$ exhibited an excellent antibacterial effectiveness against $E$. coli and $S$. aureus.

Acknowledgments: This investigation was supported by Iran University of Science and Technology and Iran's National. Elites Foundation is gratefully acknowledged.

\section{References}

1. Zhang, X.; Xia, T.; Jiang, K.; Cui, Y.; Yang, Y.; Qian, G. Highly sensitive and selective detection of mercury (II) based on a zirconium metal-organic framework in aqueous media. J. Solid State Chem. 2017, 253, 277281.

2. Xu, X.-Y.; Yan, B. Fabrication and application of a ratiometric and colorimetric fluorescent probe for $\mathrm{Hg} 2+$ based on dual-emissive metal-organic framework hybrids with carbon dots and Eu ${ }^{3+}$. J. Mater. Chem. C 2016, 4, 1543-1570.

3. Samanta, P.; Desai, A.V.; Sharma, S.; Chandra, P.; Ghosh, S.K. Selective Recognition of $\mathrm{Hg}^{2+}$ ion in Water by a Functionalized Metal-Organic Framework (MOF) Based Chemodosimeter. Inorg. Chem. 2018, 57, 2360-2364.

4. Wu, P.; Liu, Y.; Liu, Y.; Wang, J.; Li, Y.; Liu, W.; Wang, J. Cadmium-Based Metal-Organic Framework as a Highly Selective and Sensitive Ratiometric Luminescent Sensor for Mercury(II). Inorg. Chem. 2015, 54, 11046-11048.

5. Mustafa, D.; Breynaert, E.; Bajpe, S.R.; Martens, J.A.; Kirschhock, C.E. Stability improvement of Cuз(BTC)2 metal-organic frameworks under steaming conditions by encapsulation of a Keggin polyoxometalate. Chem. Comm. 2011, 47, 8037-8039.

6. Tehrani, M.S.; Zare-Dorabei, R. Highly efficient simultaneous ultrasonic-assisted adsorption of methylene blue and rhodamine B onto metal-organic framework MIL-68 (Al): Central composite design optimization. RSC Adv. 2016, 6, 27416-27425.

7. Hu, X.-J.; Liu, Y.-G.; Wang, H.; Zeng, G.-M.; Hu, X.; Guo, Y.-M.; Li, T.-T.; Chen, A.-W.; Jiang, L.-H.; Guo, F.-Y. Adsorption of copper by magnetic graphene oxide-supported $\beta$-cyclodextrin: Effects of $\mathrm{pH}$, ionic strength, background electrolytes, and citric acid. Chem. Eng. Res. Des. 2015, 93, 675-683.

8. Tehrani, M.S.; Zare-Dorabei, R. Competitive removal of hazardous dyes from aqueous solution by MIL-68 (Al): Derivative spectrophotometric method and response surface methodology approach. Spectrochim. Acta Part A 2016, 160, 8-18.

9. Oubagaranadin, J.U.K.; Murthy, Z. Adsorption of divalent lead on a montmorillonite-Illite type of clay. Ind. Eng. Chem. Res. 2009, 48, 10627-10636.

10. Esrafili, L.; Safarifard, V.; Tahmasebi, E.; Esrafili, M.; Morsali, A. Functional group effect of isoreticular metal-organic frameworks on heavy metal ion adsorption. New J. Chem. 2018, 42, 8864-8873.

11. Tahmasebi, E.; Masoomi, M.Y.; Yamini, Y.; Morsali, A. Application of mechanosynthesis azine-decorated zinc (II) metal-organic frameworks for highly efficient removal and extraction of some heavy metal ions from aqueous samples: A comparative study. Inorg. Chem. 2014, 54, 425-433.

12. Xiong, Y.Y.; Wu, H.Q.; Luo, F. The MOF+ Technique: A Potential Multifunctional Platform. Chem. Eur. J. 2018, 24, 13701-13705. 
13. Jin, H.-G.; Zong, W.; Yuan, L.; Zhang, X.-B. Nanoscale zeolitic imidazole framework-90: Selective, sensitive and dual-excitation ratiometric fluorescent detection of hazardous $\mathrm{Cr}$ (VI) anions in aqueous media. New J. Chem. 2018, 42, 12549-12556.

14. Zheng, T.-T.; Zhao, J.; Fang, Z.-W.; Li, M.-T.; Sun, C.-Y.; Li, X.; Wang, X.-L.; Su, Z.-M. A luminescent metalorganic framework with high sensitivity for detecting and removing copper ions from simulated biological fluids. Dalton Trans. 2017, 46, 2456-2461.

15. Xiong, Y.Y.; Li, J.Q.; le Gong, L.; Feng, X.F.; Meng, L.N.; Zhang, L.; Meng, P.P.; Luo, M.B.; Luo, F. Using MOF-74 for $\mathrm{Hg}^{2+}$ removal from ultra-low concentration aqueous solution. J. Solid State Chem. 2017, 246, 1622.

16. Kuppler, R.J.; Timmons, D.J.; Fang, Q.-R.; Li, J.-R.; Makal, T.A.; Young, M.D.; Yuan, D.; Zhao, D.; Zhuang, W.; Zhou, H.-C. Potential applications of metal-organic frameworks. Coord. Chem. Rev. 2009, 253, 30423066.

17. Kazemi, S.; Safarifard, V. Carbon dioxide capture in MOFs: The effect of ligand functionalization. Polyhedron 2018, 154, 236-251.

18. Moradia, E.; Rahimib, R.; Safarifardc, V. Sonochemical synthesis of fabrication nanoporous metal-organic framework base on tetrakis (4-carboxyphenyl) porphyrin (TCPP) linker. In Proceedings of the 21st International Electronic Conference on Synthetic Organic Chemistry, Santiago de Compostela, Spain, 1-30 November 2017.

19. Eddaoudi, M.; Kim, J.; Rosi, N.; Vodak, D.; Wachter, J.; O'Keeffe, M.; Yaghi, O.M. Systematic design of pore size and functionality in isoreticular MOFs and their application in methane storage. Science 2002, 295, 469472.

20. Kreno, L.E.; Leong, K.; Farha, O.K.; Allendorf, M.; van Duyne, R.P.; Hupp, J.T. Metal-organic framework materials as chemical sensors. Chem. Rev. 2011, 112, 1105-1125.

21. Khezerloo, E.; Mousavi-khoshdel, S.M.; Safarifard, V. Sensitive and selective detection of metal ions and small molecules in aqueous media using a hydrolytically stable amide-functionalized metal-organic framework. Polyhedron 2019, 166, 166-174.

22. Tanhaei, M.; Mahjoub, A.R.; Safarifard, V. Energy-efficient sonochemical approach for the preparation of nanohybrid composites from graphene oxide and metal-organic framework. Inorg. Chem. Commun. 2019, 102, 185-191.

23. Zhao, Y.; Seredych, M.; Zhong, Q.; Bandosz, T.J. Superior performance of copper-based MOF and aminated graphite oxide composites as CO2 adsorbents at room temperature. ACS Appl. Mater. Interfaces 2013, 5, 4951-4959.

24. Johnson, J.A. Design and Synthesis of Novel Octacarboxy Porphyrinic Metal-Organic Frameworks. Ph.D. Thesis, University of Nebraska-Lincoln, Lincoln, NE, USA, 2016.

25. Horcajada, P.; Gref, R.; Baati, T.; Allan, P.K.; Maurin, G.; Couvreur, P.; Ferey, G.; Morris, R.E.; Serre, C. Metal-organic frameworks in biomedicine. Chem. Rev. 2011, 112, 1232-1268.

26. Masoomi, M.Y.; Morsali, A. Applications of metal-organic coordination polymers as precursors for the preparation of nano-materials. Coord. Chem. Rev. 2012, 256, 2921-2943.

27. Moradi, E.; Rahimi, R.; Safarifard, V. Sonochemically synthesized microporous metal-organic framework representing unique selectivity for detection of $\mathrm{Fe}^{3+}$ ions. Polyhedron 2019, 159, 251-258.

28. Zare, F.; Ghaedi, M.; Daneshfar, A. The headspace solid-phase microextraction of polycyclic aromatic hydrocarbons in environmental water samples using silica fiber modified by self-assembled gold nanoparticles. Anal. Methods 2015, 7, 8086-8093.

29. Roosta, M.; Ghaedi, M.; Daneshfar, A.; Sahraei, R. Ultrasound-assisted microextraction-nano material solidphase dispersion for extraction and determination of thymol and carvacrol in pharmaceutical samples: Experimental design methodology. J. Chromatogr. B 2015, 975, 34-39.

30. Asfaram, A.; Ghaedi, M.; Hajati, S.; Goudarzi, A. Synthesis of magnetic $\gamma$-Fe $\mathrm{F}_{2} \mathrm{O}_{3}$-based nanomaterial for ultrasonic-assisted dyes adsorption: Modeling and optimization. Ultrason. Sonochem. 2016, 32, 418-431.

31. Suslick, K.S.; Didenko, Y.; Fang, M.M.; Hyeon, T.; Kolbeck, K.J.; McNamara, W.B., III; Mdleleni, M.M.; Wong, M. Acoustic cavitation and its chemical consequences, Philosophical Transactions of the Royal Society of London. Series A: Mathematical. Phys. Eng. Sci. 1999, 357, 335-353. 
32. Zare-Dorabei, R.; Ferdowsi, S.M.; Barzin, A.; Tadjarodi, A. Highly efficient simultaneous ultrasonicassisted adsorption of $\mathrm{Pb}$ (II), $\mathrm{Cd}$ (II), $\mathrm{Ni}$ (II) and $\mathrm{Cu}$ (II) ions from aqueous solutions by graphene oxide modified with 2, 2'-dipyridylamine: Central composite design optimization. Ultrason. Sonochem. 2016, 32, 265-276.

33. Dashamiri, S.; Ghaedi, M.; Dashtian, K.; Rahimi, M.R.; Goudarzi, A.; Jannesar, R. Ultrasonic enhancement of the simultaneous removal of quaternary toxic organic dyes by $\mathrm{CuO}$ nanoparticles loaded on activated carbon: Central composite design, kinetic and isotherm study. Ultrason. Sonochem. 2016, 31, 546-557.

34. Jamshidi, M.; Ghaedi, M.; Dashtian, K.; Hajati, S.; Bazrafshan, A. Sonochemical assisted the hydrothermal synthesis of $\mathrm{ZnO}$ : $\mathrm{Cr}$ nanoparticles loaded activated carbon for simultaneous ultrasound-assisted adsorption of ternary toxic organic dye: Derivative spectrophotometric, optimization, kinetic and isotherm study. Ultrason. Sonochem. 2016, 32, 119-131.

35. Azad, F.N.; Ghaedi, M.; Dashtian, K.; Hajati, S.; Pezeshkpour, V. Ultrasonically assisted hydrothermal synthesis of activated carbon-HKUST-1-MOF hybrid for efficient simultaneous ultrasound-assisted removal of ternary organic dyes and antibacterial investigation: Taguchi optimization. Ultrason. Sonochem 2016, 31, 383-393.

36. Jamshidi, M.; Ghaedi, M.; Dashtian, K.; Ghaedi, A.; Hajati, S.; Goudarzi, A.; Alipanahpour, E. Highly efficient simultaneous ultrasonic-assisted adsorption of brilliant green and eosin B onto ZnS nanoparticles loaded activated carbon: Artificial neural network modeling and central composite design optimization. Spectrochim. Acta A 2016, 153, 257-267.

37. Nakamoto, K. Infrared and Raman Spectra of Inorganic and Coordination Compounds, 5th ed.; John Wiley and Sons: New York, NY, USA, 1997.

38. Pramanik, S.; Zheng, C.; Zhang, X.; Emge, T.J.; Li, J. New Microporous Metal-Organic Framework Demonstrating Unique Selectivity for Detection of High Explosives and Aromatic Compounds. J. Am. Chem. Soc. 2011, 133, 4153-4155.

39. Moradi, E.; Rahimi, R.; Davoudabadi Farahani, Y.; Safarifard, V. Porphyrinic zirconium-based MOF with exposed pyrrole Lewis base site as a luminescent sensor for highly selective sensing of $\mathrm{Cd}^{2+}$ and $\mathrm{Br}^{-}$ions and THF small molecule. J. Solid-State Chem. 2020, 822, 121103.

40. Kim, J.; Yang, S.-T.; Choi, S.B.; Sim, J.; Kim, J.; Ahn, W.-S. Control of catenation in CuTATB-n metal-organic frameworks by sonochemical synthesis and its effect on CO2 adsorption. J. Mater. Chem. 2011, 21, 30703076.

41. Zhou, X.; Li, H.; Xiao, H.; Li, L.; Zhao, Q.; Yang, T.; Zuo, J.; Huang, W. A microporous luminescent europium metal-organic framework for nitroexplosive sensing. Dalton Trans. 2013, 42, 5718-5723.

42. Gedanken, A. Using sonochemistry for the fabrication of nanomaterials. Ultrason. Sonochem. 2004, 11, 4755.

43. Li, J.; Wang, X.; Zhao, G.; Chen, C.; Chai, Z.; Alsaedi, A.; Hayat, T.; Wang, X. Metal-organic frameworkbased materials: Superior adsorbents for the capture of toxic and radioactive metal ions. Chem. Soc. Rev. 2018, 47, 2322-2356.

44. Li, J.; Wu, Y.; Song, F.; Wei, G.; Cheng, Y.; Zhu, C. A highly selective and sensitive polymer-based OFF-ON fluorescent sensor for $\mathrm{Hg}^{2+}$ detection incorporating salen and perylenyl moieties. J. Mater. Chem. 2012, 22, $478-483$.

45. Wang, J.; Zhang, W.; Yue, X.; Yang, Q.; Liu, F.; Wang, Y.; Zhang, D.; Li, Z.; Wang, J. One-pot synthesis of multifunctional magnetic ferrite-MoS - carbon dot nanohybrid adsorbent for efficient $\mathrm{Pb}$ (II) removal. J. Mater. Chem. A 2016, 4, 3893-3900.

46. Singbumrung, K.; Motina, K.; Pisitsak, P.; Chitichotpanya, P.; Wongkasemjit, S.; Inprasit, T. Preparation of Cu-BTC/PVA Fibers with Antibacterial Applications. Fibers Polym. 2018, 19, 1373-1378.

47. Nabipour, H.; Soltani1, B.; Nasab, N.A. Gentamicin Loaded Zn2(bdc)2(dabco) Frameworks as Efficient Materials for Drug Delivery and Antibacterial Activity. J. Inorg. Organometal. Poly Mater. 2018, 28, 12061213.

48. Nabipour, H.; Sadr, M.H.; Bardajee, G.R. Release behavior, kinetic and antimicrobial study of nalidixic acid from $\left[\mathrm{Zn}_{2}(\mathrm{bdc})_{2}(\mathrm{dabco})\right]$ metal-organic frameworks. J. Coord. Chem. 2017, 70, 2771-2784.

(C) 2019 by the authors. Licensee MDPI, Basel, Switzerland. This article is an open access article distributed under the terms and conditions of the Creative Commons Attribution (CC BY) license (http://creativecommons.org/licenses/by/4.0/). 